Available online at GSC Online Press Directory

GSC Biological and Pharmaceutical Sciences

e-ISSN: 2581-3250, CODEN (USA): GBPSC2

Journal homepage: https://www.gsconlinepress.com/journals/gscbps

(RESEARCH ARTICLE)

\title{
Salt concentration effect on yeast diversity of the Ivorian traditional fermented fish adjuevan
}

Kouakou-Kouamé Amenan Clémentine ${ }^{1,2,{ }^{*},}$ N guessan Kouadio Florent ${ }^{1}$, Aka Solange ${ }^{1}$, Montet Didier ${ }^{2}$ and Djè Koffi Marcellin ${ }^{1}$

${ }^{1}$ Laboratory of Biotechnology and Food Microbiology, Department of Food Science and Technology, Nangui Abrogoua University,02 BP 801 Abidjan 02, Côte d'Ivoire.

${ }^{2}$ Centre for International Cooperation in Agronomic Research for Development, CIRAD, UMR Qualisud, Montpellier 34398, France.

Publication history: Received on 30 July 2020; revised on 11 August 2020; accepted on 18 August 2020

Article DOI: https://doi.org/10.30574/gscbps.2020.13.1.0248

\begin{abstract}
This study aimed to investigate the yeast diversity in adjuevan fermented at the laboratory scale according to salt concentration following both traditional fermentation methods. Thus, the fish species Galeoides decadactylus was fermented with salt added at $10 \%, 15 \%, 20 \%, 25 \%$ and $30 \%$ (w/w) for five days. Yeast identification using PCRDDGE method reveled seven species which were Pichia fermentans, Candida zeylanoides, Candida sp, Hanseniaspora osmophila, Kluyveromyces sp; Torulaspora delbrueckii and Kluyveromyces marxianus. These species varied according to fermentation method used and salt concentration added with Pichia fermentans and Hanseniaspora osmophila as dominant strains. These results showed also that Kluyveromyces marxianus and Torulaspora delbrueckii were more tolerant to sodium chloride than the others. This work confirmed that yeasts were involved and participated in adjuevan production. Therefore, these yeasts should be tested for their functionality during the fermentation, and some might be useful as starter culture to produce better quality fermented fish adjuevan.
\end{abstract}

Keywords: Adjuevan; Fermented fish; Yeasts; PCR-DGGE; Salt

\section{Introduction}

In most tropical countries, traditional processes such as drying, salting, smoking, and fermentation are used for fresh fish preservation. Ivorian fermented fish adjuevan, like various traditional fermented fish products in the world, was produced by spontaneous fermentation and used as flavoring in foods. Adjuevan is a salted fermented fish product mostly produced according to two different traditional methods at ambient temperature $\left(28-30{ }^{\circ} \mathrm{C}\right)$ by Ivorian women in the center and south of the country. In the method 1, the entire fish was allowed to deteriorate in air for $48 \mathrm{~h}$, eviscerated, washed, and dry salted at around $35 \%(\mathrm{w} / \mathrm{w})$. Thereafter, the salted fish was allowed to ferment for 5 days and sun dried for 4 days at ambient temperature. For method 2, the entire fish was allowed to deteriorate in air for 24 $\mathrm{h}$, gutted, filleted along both sides, washed, and dry salted at 20 35 \% (w/w). Fermentation was carried out outside at room temperature, simultaneously with sun-drying on racks or nets, for at least 7 days [1]. These methods lead to visually two different end-products. Previous studies that have evaluated the microbial communities in adjuevan found the dominant species to belong to the genera Bacillus and Staphylococcus with the bacteria community varied according to the method used [2]. On the other hand, by using culture-depend methods, Koffi-Nevry et al. [3] showed that Lactobacillus fermentum was the dominant lactic acid bacteria species while the report of Kouakou et al. [4-5] using PCR-DGGE showed Lactobacillus fermentum, Leuconostoc lactis subsp lactis, Pediococcus pentosaceus for method 1 and

\footnotetext{
${ }^{*}$ Corresponding author: Kouakou-Kouamé Amenan Clémentine

Laboratory of Biotechnology and Food Microbiology, Department of Food Science and Technology, Nangui Abrogoua University,02 BP 801 Abidjan 02, Côte d'Ivoire
} 
Pediococcus pentosaceus, Lactococcus garviae, Streptococcus difficilis for method 2 as the dominant lactic acid bacteria species.

Yeasts are one of the predominant groups among the microbial population throughout most of the fermentation process in several food and beverage production. Yeasts are ubiquitous microorganisms, which can grow in various environments where organic substrates are available and capable of growing and multiplying on complex substrates with high amounts of sugar, salt, low pH, low temperature and low water activity (aw) [6]. Previous studies that have investigated the yeast communities in adjuevan samples collected from traditional producers in the south of Côte d'Ivoire found height species belonging to several genera with variation depending to the fermentation method. These yeasts could be advantageous for adjuevan flavor like some lactic acid bacteria [7]. In fact, different yeast strains have been reported to influence the development of the flavour characteristic of dry-cured meat products, Martin et al. [8]. However, the presence of yeasts on food products may also considered as an indication of food spoilage [9]. Then yeasts may cause yeasty or bitter taste, change in colour and texture of products and may deform or blow up packaging materials and could also be an underestimated source of infections and adverse health responses [10]. Thus, yeasts found in adjuevan could be from contamination during the production by material of production, salt or others [7]. The dual role as beneficial or spoilage organisms have attracted the interests of this study to understand their significance for adjuevan product. Furthermore, the percentage of salt added during adjuevan fermentation varied according to the producer.

The purpose of this study was to investigate the yeast diversity on adjuevan produced in laboratory according to different salt concentrations following both fermentation methods.

\section{Material and methods}

\subsection{Adjuevan production}

Fresh fish (Galeoides decadactylus) was bought from two traditional producers of adjuevan at Vridi-port. Four samples of $4 \mathrm{~kg}$ of fresh fish each, was taken per traditional producer and then divided into four different sterile containers of 1 $\mathrm{kg}$ each. Then samples of fresh fish were taken to the laboratory for adjuevan production according to the two main traditional fermentation processing methods used by local producers as described by Kouakou et al. [1] and Montet et al. [2]. This adjuevan production was done using different concentrations of salt (w/w): $10 \%, 15 \%, 20 \%, 25 \%$ and 30 $\%$. Samples were collected just after five days of fermentation for analysis. Fermentation experiments were conducted in triplicate.

\subsection{Chemical analysis}

The following physicochemical analyses were performed: $\mathrm{pH}, \mathrm{Aw}$, salt content and titratable acidity. Sodium content was determined by a chloride analyser (Corning Chloride analyser 926) after cold extraction in $0.3 \mathrm{~N}$ nitric acid [11]. Water activity was determined using a water activity meter (AQUA LAB 4TE Decagon Devices fashion). pH and titratable acidity were determined by an automatic titrimeter (TitroLine easy Schott 96) on $5 \mathrm{~g}$ of fermented fish dissolved in 50 $\mathrm{ml}$ distilled water after homogenization during $30 \mathrm{~min}$, then titrated by $0.05 \mathrm{~N} \mathrm{NaOH}$.

\subsection{Enumeration of microorganisms}

For all determinations, $10 \mathrm{~g}$ of adjuevan sample was added aseptically to $90 \mathrm{ml}$ of sterile diluent containing $0.1 \%$ peptone (Oxoid, Basingstoke, UK) and $0.85 \% \mathrm{NaCl}$ (Merck, Darmstadt, Germany), with the pH adjusted to 7.2, and homogenized in a stomacher (lab blender; Seward Medical, London, UK) for $30 \mathrm{~s}$ at normal speed. Lactic acid bacteria (LAB) and Micrococcaceae were enumerated using Man Rogosa and Sharpe agar (MRS ; bioMerieux, Marcy l'Etoile, France) and mannitol salt agar (MSA ; Oxoid), respectively. Plates were incubated at $30^{\circ} \mathrm{C}$ for $48 \mathrm{~h}$. Yeast enumeration was done using malt extract agar (MEA) (Oxoid) containing $0.1 \%$ oxytetracycline (Sigma-Aldrich Co., USA). The MEA plates were incubated at $25^{\circ} \mathrm{C}$ for 4 days. After the incubation, a differential count based on colony color and aspect was made.

\subsection{Statistical analysis}

Results were statistically evaluated by one-way analysis of variance (ANOVA) and Bonferroni test (Dunn) with the software Statistica, 99 Edition. Statistical differences with $\mathrm{p}<0.05$ were considered significant. 


\subsection{Molecular analysis}

\subsubsection{DNA extraction from yeast}

DNA extraction from yeast was done according to El Sheikha et al. [12]. About $10 \mathrm{~g}$ of fermented fish samples taken from skin, abdomen and head were homogenized by vortex for $30 \mathrm{~min}$ (Vortex Genie 2 SI-A256, USA) after addition of $16 \mathrm{ml}$ of sterile peptone water (pH 7.0, Dickinson, France). Two Eppendorf tubes of $2 \mathrm{ml}$ containing the homogenate were vortexed for $10 \mathrm{~min}$ and centrifuged at $12000 \mathrm{~g}$ for $15 \mathrm{~min}$, then the supernatant was discarded. The cell pellet was resuspended in $300 \mu \mathrm{l}$ of breaking buffer [ $2 \%$ Triton X-100 (Prolabo, France), $1 \%$ SDS (sodium dodecyl sulphate; Sigma, France), $100 \mathrm{mM} \mathrm{NaCl}$ (Sigma), $10 \mathrm{mM}$ Tris, pH 8.0, 1 mM EDTA, pH 8.0 (Promega, France)]. A volume of $100 \mu \mathrm{l}$ TE [10 $\mathrm{mM}$ Tris-HCl; $1 \mathrm{mM}$ EDTA; pH 8.0 (Promega)], $100 \mu$ lysozyme solution (25 mg/ml, Eurobio, France), and $100 \mu \mathrm{l}$ proteinase $\mathrm{K}$ solution (20 mg/ml, Eurobio, France)] were added and the mixture was incubated at $42{ }^{\circ} \mathrm{C}$ for $20 \mathrm{~min}$. Then $50 \mu \mathrm{l}$ of $20 \%$ SDS were added to each tube, and then incubated at $42{ }^{\circ} \mathrm{C}$ for $10 \mathrm{~min}$. $400 \mu \mathrm{l}$ MATAB (mixed alkyltrimethyl ammonium bromide; Sigma) were added to each tube, and then incubated at $65{ }^{\circ} \mathrm{C}$ for $10 \mathrm{~min}$. The lysates were then purified twice by repeated extraction with $700 \mu \mathrm{l}$ phenol/chloroform/isoamyl alcohol (25/24/1; Carlo Erba, France), and the tubes were vortexed for $1 \mathrm{~min}$ and centrifuged at $12000 \times g$ for $15 \mathrm{~min}$. The aqueous layer was transferred to an Eppendorf vial and the residual phenol was removed by extraction with $600 \mu \mathrm{l}$ chloroform/isoamyl alcohol (24/1), and centrifuged for $15 \mathrm{~min}$ at $12000 \times \mathrm{g}$. The aqueous phase was collected and the DNA was stabilized with $30 \mu \mathrm{l}$ sodium acetate ( $3 \mathrm{M}, \mathrm{pH} 5)$, followed by precipitation by adding an equal volume of ice-cold isopropanol, and stored at $-20^{\circ} \mathrm{C}$ for $12 \mathrm{~h}$ (overnight). After centrifugation at $12000 \times \mathrm{g}$ for $15 \mathrm{~min}$, the supernatant was eliminated, DNA pellets were washed with $500 \mu \mathrm{l} 70 \%$ ethanol, and the tubes were centrifuged at $12000 \times g$ for 15 min. The ethanol was then discarded and the pellets were air-dried at room temperature for $3 \mathrm{~h}$. Finally, the DNA was resuspended in $50 \mu \mathrm{l}$ of ultrapure water and stored at $-20^{\circ} \mathrm{C}$ until analysis.

\subsubsection{PCR-Denaturing Gradient Gel Electrophoresis (DGGE) analysis}

A fragment of the D1/D2 region of the 26S rRNA gene was amplified using eukaryotic universal primers NL1GC and LS2 amplifying a $250 \mathrm{bp}$ fragment [13- 12]. A $30 \mathrm{bp}$ GC clamp (Sigma) was added to the forward primer. PCR amplification was performed in a final volume of $50 \mu \mathrm{l}$ according to the protocols described by kouakou et al. [7]. Aliquots (5 $\mu \mathrm{l}$ ) of PCR products were analysed first by conventional electrophoresis in $2 \% \mathrm{w} / \mathrm{v}$ agarose gel with $1 \times$ TAE buffer $(40 \mathrm{mM}$ Tris-HCl, pH 7.4, $20 \mathrm{mM}$ sodium acetate, $1.0 \mathrm{mM} \mathrm{Na-EDTA),} \mathrm{stained} \mathrm{with} \mathrm{ethidium} \mathrm{bromide} \mathrm{(Promega)} 50 \mu \mathrm{g} / \mathrm{ml} \mathrm{in} 1 \times$ TAE and quantified by using a standard (100 bp DNA ladder; Promega). PCR products were analysed by DGGE, by using a Bio-Rad code universal mutation detection system (Bio-Rad, USA), following the procedure described by Leesing [14]. Samples containing approximately equal amounts of PCR amplicons were loaded into 8\% (w/v) polyacrylamide gels in $1 \times$ TAE buffer (40 mM Tris-HCl, pH 7.4, $20 \mathrm{mM}$ sodium acetate, $1.0 \mathrm{mM} \mathrm{Na-EDTA}$ ). All electrophoresis experiments were performed at $60^{\circ} \mathrm{C}$, using a denaturing gradient in the range of 30 to $60 \%$ (100\% corresponded to $7 \mathrm{M}$ urea and $40 \% \mathrm{v} / \mathrm{v}$ formamide; Promega). The gels were electrophoresed at $20 \mathrm{~V}$ for $10 \mathrm{~min}$ and then at $80 \mathrm{~V}$ for $12 \mathrm{~h}$. After electrophoresis, the gels were stained for $30 \mathrm{~min}$ with ethidium bromide and rinsed for $10 \mathrm{~min}$ in distilled water and then photographed on a UV transilluminator with the Gel Smart 7.3 system (Clara Vision, Les Ulis, France).

\subsubsection{Purification and sequencing}

Bands were cut from the gel and the amplicons were purified using the Wizard PCR purification kit (Preps DNA Purification System, Promega, France) followed by a new PCR but with primers without GC clamp. The PCR products were then sent at GATC Biotech (Germany) where they were submitted to a second DNA purification before sequencing. Sequence of 26S rDNA comparisons were performed using the basic local alignment search tool (BLAST) in GenBank (www.ncbi.nlm. nih.gov/blast) after editing and trimming the sequences by BioEdit sequence alignment editor, version 7.0.0. The yeast isolates were identified based on a 99-100 \% similarity criterion.

\section{Results and discussion}

\subsection{Chemical composition}

Chemical characteristics of adjuevan samples were ranged in Table1. The salt content in adjuevan samples was proportional to the salt concentration used for fermentation and the method of fermentation. The salt contents of adjuevan produced with $10 \%, 15 \%$ and $20 \%$ of salt $(\mathrm{w} / \mathrm{w})$ were between $2.89 \%$ and $3.71 \%$ and those obtained with $25 \%$ and $30 \%$ were around $6 \%$. Concerning the samples obtained from the second method, the salt contents observed were between $3.15 \%$ and $4.29 \%$ in the samples produced with the rates of $10 \%$ and $15 \%$ of salt (w/w) and from 5.64 to $7.36 \%$ in the samples with $20 \%$ and $30 \%$ of salt. Titratable acidity was high in samples with $10 \%$ and $15 \%$ at 13.81 $\mathrm{mg} / 100 \mathrm{~g}$ and $11.17 \mathrm{mg} / 100 \mathrm{~g}$, respectively for samples from method 1 and method 2 . This content decreased from 
$25 \%$ to $10.913 \mathrm{mg} / 100 \mathrm{~g}$ of salt in sample of method 1 and at $09.01 \mathrm{mg} / 100 \mathrm{~g}$ in samples of method 2 from $20 \%$. The highest values of water activity (Aw) were recorded on the samples obtained from $10 \%$ and $15 \%$ of salt varied for 0.91 - 0.85 to decrease up to 0.76 at $30 \%$ of salt and $0.87-0.84$ to decrease up to 0.73 at $30 \%$ of salt respectively in samples from method 1 and method 2. Significant difference $(\mathrm{p}<0.05)$ was observed between these values. In contrast, the $\mathrm{pH}$ values showed a similar trend among samples, with the pH ranging from 5.54 to 6.29 (method 1 ) and from 6.07 to 6.62 (method 2).

Table 1 Physicochemical compounds variation according salt percentage added in adjuevan after five days of fermentation.

\begin{tabular}{|c|c|c|c|c|}
\hline \multirow{2}{*}{$\begin{array}{l}\text { Salt added } \\
(\% \mathrm{w} / \mathrm{w})\end{array}$} & AW & pH & \multirow{2}{*}{$\begin{array}{l}\text { TA (mg/100g) } \\
(n=12)\end{array}$} & \multirow[t]{2}{*}{ SC (\% Nacl) } \\
\hline & Samples of & Method1 & & \\
\hline $\mathrm{pf}(10)$ & $0.91 \pm 0.12^{\mathrm{a}}$ & $5.54 \pm 0.04^{\mathrm{a}}$ & $13.09 \pm 0.15$ & $2.89 \pm 0.61^{\mathrm{a}}$ \\
\hline pf (15) & $0.85 \pm 1.02$ & $5.73 \pm 0.16$ & $13.81 \pm 0.81^{\mathrm{a}}$ & $3.20 \pm 0.44$ \\
\hline pf (20) & $0.81 \pm 0.75$ & $6.16 \pm 0.40^{\mathrm{b}}$ & $11.23 \pm 0.57$ & $3.71 \pm 0.19$ \\
\hline pf (25) & $0.77 \pm 0.41^{b}$ & $6.42 \pm 0.22$ & $10.91 \pm 0.71^{\mathrm{b}}$ & $5.15 \pm 0.26^{b}$ \\
\hline \multirow[t]{2}{*}{ pf (30) } & $0.76 \pm 1.13^{b}$ & $6.29 \pm 0.06$ & $11.52 \pm 0.24$ & $5.94 \pm 0.47^{\mathrm{b}}$ \\
\hline & Samples of & Method2 & $(n=12)$ & \\
\hline pf" (10) & $0.87 \pm 0.34^{a}$ & $6.07 \pm 0.14^{\mathrm{a}}$ & $11.17 \pm 0.13^{a}$ & $3.15 \pm 0.29 \mathrm{a}$ \\
\hline pf" (15) & $0.81 \pm 0.91$ & $6.46 \pm 0.51^{a}$ & $10.02 \pm 0.26^{b}$ & $4.29 \pm 0.83$ \\
\hline pf' (20) & $0.74 \pm 0.46^{b}$ & $6.50 \pm 0.18^{a}$ & $09.01 \pm 0.43^{b}$ & $5.64 \pm 0.50^{b}$ \\
\hline pf' (25) & $0.73 \pm 0.62 b$ & $6.58 \pm 0.20^{a}$ & $09.15 \pm 0.90$ & $6.87 \pm 0.72 b$ \\
\hline pf' (30) & $0.73 \pm 0.35$ & $6.62 \pm 0.37 \mathrm{a}$ & $09.41 \pm 0.11$ & $7.36 \pm 0.14^{c}$ \\
\hline
\end{tabular}

Means in the same row having different superscripts are significantly different $(\mathrm{P}<0.05)$, and values in the same row with same superscript are not significantly different $(\mathrm{P}>0.05)$ according each method. SC: Salt content, TA: Titratable acidity; Aw: water activity; pf: adjuevan from method1; pf ': adjuevan from method2

\subsection{Microbiological content of adjuevan}

The microbiological status of samples is summarized in Table 2. Variation in the load of microorganisms with predominance of micrococci was observed on all bacteria regardless of the fermentation method and the percentage of salt added. Strong growth of micrococci was observed from the beginning (first day) to the end (five day) of fermentation in samples from the both methods regardless the percentage of salt added.

Table 2 Mean load of the bacterial and yeast communities determined in the adjuevan according to the two methods of fermentation.

\begin{tabular}{|c|c|c|c|}
\hline Salt added $(\% \mathrm{w} / \mathrm{w})$ & LAB & yeasts & Micrococci \\
\hline & Samples of & Method 1 & $(n=12)$ \\
\hline pf' (10) & $3.91 \pm 0.0210^{5 a}$ & $3.02 \pm 0.1210^{1 b}$ & $6.02 \pm 0.0310^{4 b}$ \\
\hline pf' (15) & $5.44 \pm 0.1110^{5 a}$ & $5.12 \pm 0.2210^{2 a}$ & $4.28 \pm 0.0110^{6}$ \\
\hline $\mathrm{pf}^{\prime}(20)$ & $7.41 \pm 0.3110^{4}$ & $3.6 \pm 0.0410^{1}$ & $7.61 \pm 0.0210^{6 a}$ \\
\hline pf' (25) & $6.13 \pm 0.0110^{4}$ & $4.67 \pm 0.0210^{1}$ & $3.51 \pm 0.0610^{5}$ \\
\hline $\mathrm{pf}^{\prime}(30)$ & $5.14 \pm 0.2310^{3 b}$ & $4.08 \pm 0.0510^{2}$ & $5.09 \pm 0.1510^{5}$ \\
\hline Salt added (\% p/p) & Samples of & Method 2 & $(n=12)$ \\
\hline $\mathrm{pf}^{\prime \prime}(10)$ & $5.35 \pm 0.0410^{4 a}$ & $2.52 \pm 0.0510^{2}$ & $4.58 \pm 0.3310^{6 a}$ \\
\hline pf" (15) & $3.95 \pm 0.0110^{2 b}$ & $4.71 \pm 1.0310^{1}$ & $5.62 \pm 0.0110^{5}$ \\
\hline pf" $(20)$ & $6.98 \pm 0.2410^{2}$ & $3.57 \pm 0.0410^{2 \mathrm{a}}$ & $6.93 \pm 0.0310^{5}$ \\
\hline pf" (25) & $5.93 \pm 0.3010^{3}$ & $4.64 \pm 0.1310^{1}$ & $4.46 \pm 0.2010^{6}$ \\
\hline pf" (30) & $4.91 \pm 0.2110^{2}$ & $2.43 \pm 0.0710^{1 \mathrm{~b}}$ & $2.89 \pm 1.0110^{4 b}$ \\
\hline
\end{tabular}

Means in the same row having different superscripts are significantly different $(\mathrm{P}<0.05)$, and values in the same row with same superscript are not significantly different $(\mathrm{P}>0.05)$ according each method.

pf : adjuevan from method1. ; pf : adjuevan from method 2 ; LAB : lactic acid bacteria 
The lactic acid bacteria (LAB) load increased at $15 \%$ of salt from $5.44 \pm 0.1110^{5} \log$ (CFU / g) to decrease to $5.1410^{3}$ $\log$ (CFU / g) at $30 \%$ of salt and $5.35 \pm 0.0410^{4} \log$ (CFU / g) in sample with $10 \%$ of salt to decrease to $4.91 \pm 0.2110^{2}$ $\log$ (CFU / g) at $30 \%$ of salt, respectively in samples of method 1 and method 2. The loads of lactic acid bacteria decreased after $15 \%$ of salt and $10 \%$ of salt respectively in the samples of method 1 and method 2 . The highest values of Lactic acid bacteria (LAB) loads were recorded on the samples from method 1 obtained with $10 \%$ and $15 \%$ of salt. However, yeasts loads were very little with the higher of 5.12 $\pm 0.2210^{2} \log$ (CFU / g) in samples with $10 \%$ of salt and $3.57 \pm 0.0410^{2} \log$ (CFU / g) $15 \%$ of salt, respectively following method 1 and method 2 .

Population growth dynamics of the yeast during the fermentations were monitored from first days to the five days (Fig. 1A; 1B). Results indicated that, according the method 1, generally, a lag phase was observed until to three days or four days according to samples with $10 \%$ to $20 \%$ of salt. But concerning samples of the second method, yeast loads decreased at the second day of fermentation then increased with an exponential growth in sample fermented with 10 $\%$ of salt $(\mathrm{w} / \mathrm{w})$. The variation in yeast populations during fermentation was more influenced by the methods used than by the salt concentrations added.
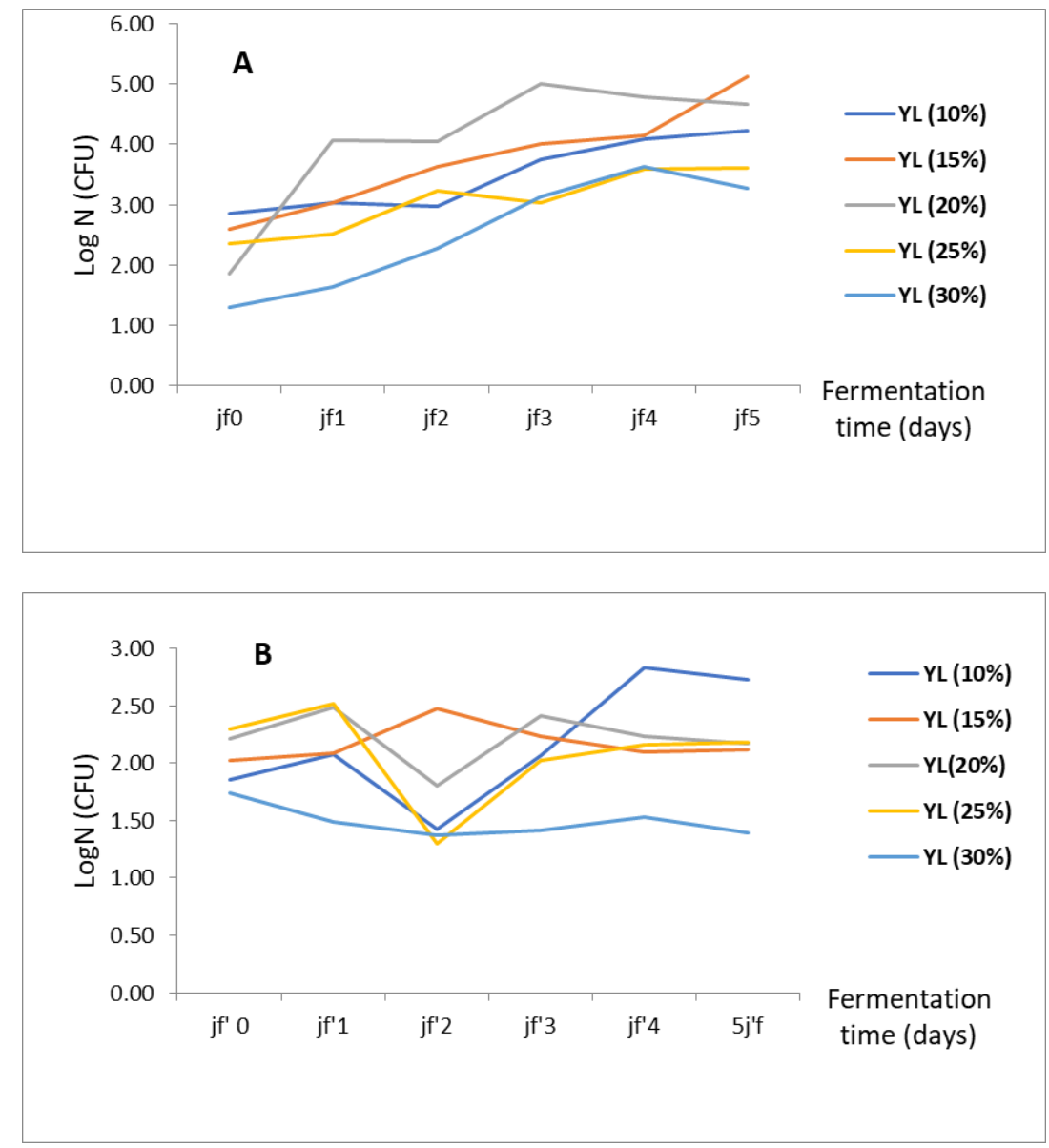

Figure 1 Yeasts evolution during adjuevan fermentation according salt concentration added

A=Yeasts growth during adjuevan fermentation for method 1; B=Yeasts growth during adjuevan fermentation for method; YL: yeast load; \%: salt concentration added for fermentation; jf: fermentation following method1; jf: fermentation day following method2

\section{DGGE profiles of the yeast community}

The PCR-DGGE profiles of the fermented fish adjuevan revealed the presence of 5 to 8 DNA bands from yeasts (Fig. 2) following method used and percentage of salt added for the fermentation. So, 8 bands were present in the samples of method 1 and 5 bands in the samples of method 2. In sample from method 1, on the bases of these yeast profiles, three sample groups could be distinguished: (i) samples produced with $10 \%$ and $25 \%$ salt which gave two more different bands; (ii) those with $15 \%$ and $20 \%$ salt gave the same profile with one more band and (iii) samples of $30 \%$ of salt with only 2 bands. 

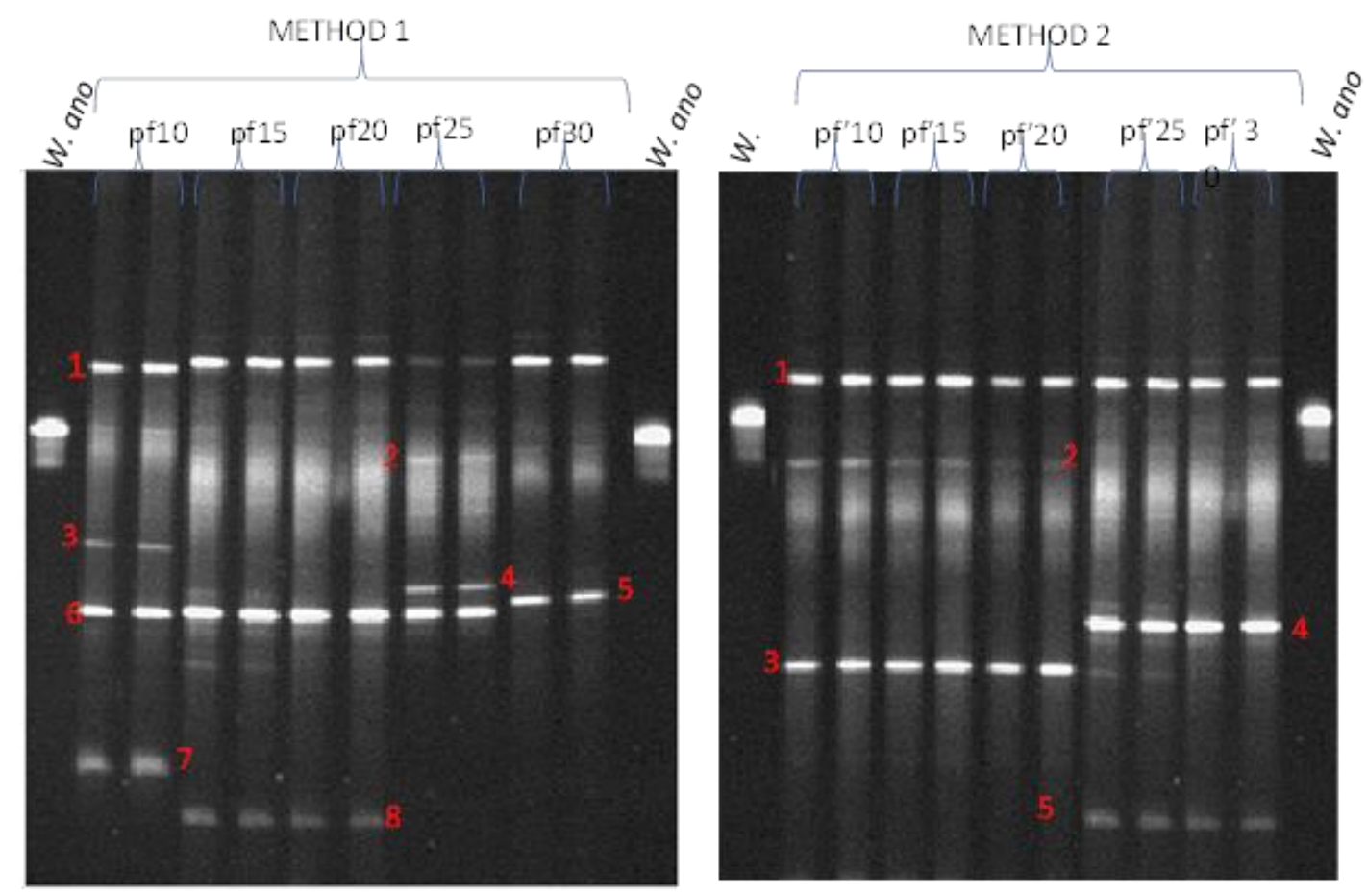

Figure 2 DGGE profiles of the yeasts community from DNA directly extracted from adjuevan produced with two traditional processing methods at laboratory scale.

Bands indicated by numbers were excised and, after re-amplification, subjected to sequencing. Yeasts diversity were: For Method: 1- Pichia fermentans; 2. Candida zeylanoides; 3. Candida sp; 4. Kluyveromyces marxianus; 5.Kluyveromyces sp; 6. Hanseniaspora osmophila

For Method2 : 1. Pichia fermentans ; 2. Candida zeylanoides ; 3. Hanseniaspora osmophila ; 4. Torulaspora delbrueckii.

However, DGGE profile of the samples of method 2 showed five bands in general which could be grouped in two groups according to salt concentration. The first group composed of samples of $10 \%, 15 \%$ and $20 \%$ salt showed the same profile of three bands while the second group, those of $25 \%$ and $30 \%$ of salt, showed identic profile of three bands. These yeasts bands on the DGGE profile were sequenced and the species were identified (Table 3). According to samples from method 1, six closely species were found: Pichia fermentans, Candida zeylanoides, Candida sp, Hanseniaspora osmophila, Kluyveromyces sp and Kluyveromyces marxianus. On the bases of these yeast species profiles, four samples groups following salt concentration could be distinguished : (i) samples of $10 \%$ of salt showed three species which were Pichia fermentans, Hanseniaspora osmophila and Candida sp; (ii) samples of $15 \%$ and $20 \%$ of salt witch showed only two species: Pichia fermentans and Hanseniaspora osmophila; (iii) samples of $25 \%$ of salt with three species: Pichia fermentans, Hanseniaspora osmophila and Kluyveromyces marxianus; (iii) samples of $30 \%$ of salt with three species : Pichia fermentans and Kluyveromyces sp. Concerning samples of method 2, four species were identified: Pichia fermentans, Candida zeylanoides, Hanseniaspora osmophila and Torulaspora delbrueckii. Only two sample groups following salt concentration, on the bases of these yeast species profiles, could be distinguished: (i) samples of $10 \%$, 15 $\%$ and $20 \%$ of salt showed three species named Pichia fermentans, Candida zeylanoides and Hanseniaspora osmophila and (ii) samples of $25 \%$ and $30 \%$ of salt with Pichia fermentans and Torulaspora delbrueckii. The most frequently identified species from adjuevan samples of the both methods used, without salt added were Pichia fermentans and Hanseniaspora osmophila. An exception to theses grouping, among species, difference was made between the both methods again. Then two genera such us Candida $s p$ and Kluyveromyces $s p$ were observed only in samples for method 1 contrary to method 2 which was characterized by the presence of one specie (Torulaspora delbrueckii) seen exceptionally in samples of $25 \%$ and $30 \%$ of salt. 
Table 3 Identity of bands obtained from the denaturing gradient gel electrophoresis analysis of adjuevan yeasts communities.

\begin{tabular}{lllll}
\hline Closest relative & Identity \% & Source & \multicolumn{2}{l}{ Band number } \\
\hline & & & Method 1 & Method2 \\
\hline Pichia fermentans & 100 & EU019222 & 1 & 1 \\
Candida zeylanoides & 98 & AF374610 & 2 & 2 \\
Torulaspora delbrueckii & 99 & AB436465 & X & $\mathbf{4}$ \\
Candida sp & 97 & EU651854 & $\mathbf{3}$ & $\mathrm{X}$ \\
Hanseniaspora osmophila & 100 & HQ149312 & 6 & 3 \\
Kluyveromyces marxianus & 99 & DQ139802 & $\mathbf{4}$ & $\mathrm{X}$ \\
Kluyveromyces sp & 98 & EU019220 & $\mathbf{5}$ & $\mathrm{X}$ \\
\hline
\end{tabular}

\section{Discussion}

Chemical compounds varied following salt concentration added during fermentation. The pH and salt content were low with highest water activity and titratable acidity in all samples of $10 \%$ and $15 \%$ salt. The salt concentration increase induces the increase of $\mathrm{pH}$ around 6 but a decrease of water activity especially in sample from method 2. This is favored by the large contact surface between the salt and the flesh of the fish by the fact that the fish were open. Our results are in agreement with those of Barat et al. [15] who showed that the larger the surface of contact with salt, the greater the penetration with a significant effect on the driving forces in the system (activity of the water, osmotic pressure and salt gradient).

More attention was given to understand the dynamic of fish salting [16]. Theses authors showed the relationships between salt diffusivity and fish fillet compound under various conditions. $\mathrm{NaCl}$ values measured in this study varied following salt concentration and fermentation method used which is in accordance with those reported by Anihouvi et al. [17]. Regarding the analysis of microbial flora, this study showed in general a dominance of micrococci, high presence of lactic acid bacteria and especially lowest count of yeasts in fermented fish samples. LAB counts were ranged between $10^{3}-10^{5} \mathrm{Log}$ UFC/g according method 1 and 102-104 Log UFC/g for method 2. The dominance of the micrococci in the present study may indicate that the fermentation was proteolytic and lipolytic. Such results have also been reported by Achinewhu et al. [18] and Anihouvi et al. [19] in the case of fermented sardines from Nigeria and lanhouin from Benin. In contrast of $\mathrm{LAB}$, yeast enumeration showed a low load in samples generally around $10^{1}-10^{2} \mathrm{Log}$ UFC/g regardless the method used. This result has been reported in momoni [20] and the plaa-som [21]. In this study, these lowest loads of yeasts varied exclusively according to the fermentation method used. This result can also be explained by the fact that yeasts are capable of growing and multiplying on complex substrates with high amounts of sugar, salt, low pH, low temperature and low water activity [6].

Identification of yeasts revealed seven (7) species as Pichia fermentans, Candida zeylanoides, Candida sp, Hanseniaspora osmophila, Kluyveromyces sp, Kluyveromyces marxianus and Torulaspora delbrueckii. The yeast diversity found using both traditional fermentation methods in adjuevan was similar. Therefore, the use of both approaches is considered more comprehensive for a full description of the yeast populations in these products. These yeasts were present on adjuevan produced at the laboratory scale as well as those produced by traditional producers. Kouakou et al. [7] have reported, having identified the species such as Pichia fermentans, Hanseniaspora osmophila and Kluyveromyces marxianus on the adjuevan collected with traditional producers in the south of Côte d'Ivoire. It showed that these species could come from the marine origin of the fresh fish but not from contamination linked to fermentation materials used or the environment as reported by Sanni et al. [20] and Kouakou et al. [7]. There could therefore contribute positively to fermentation of the adjuevan such as the development of the characteristic flavour. Pichia fermentans and Hanseniaspora osmophila were found dominants strains in all samples regardless salt added, then the same yeast species have been found important in other adjuevan samples from traditional producers by Kouakou et al. [7]; which suggests a distinct contribution of the species to the fermentation of adjuevan. These yeasts growth may play either a beneficial role, to generate arrays of volatile and non-volatile metabolites [22], so positive contribution for the development of sensory qualities of adjuevan. Their metabolites can affect the chemosensory properties of the adjuevan products, important to consumers. Yeasts on the surface of adjuevan could also be used as probiotics and serve as bio- 
control agents against pathogenic microorganisms like in the case of dry-cured meat products and cheeses according to Alvarez-Martin et al. [23]; Jacques and Casaregola [9]; Asefa et al. [24]. Candida zeylanoides was found in adjuevan from the both methods. This specie has been found dominate from the Italian and spanish dry-cured meat products during fermentation [25-10]. However, Nielsen et al. [26] and Asefa et al. [24] have taxed this specie to be an emerging pathogen. So, it could have a pathogenic potential in adjuevan, dangerous for consumers. Moreover, Torulaspora delbrueckii which had never be described previously in adjuevan and Kluyveromyces marxianus have been found only in adjuevan produced at 25-30\% salt with method 2 and method 1, respectively. These yeast species frequently associated with meat products spoilage [27] could participate to adjuevan spoilage. The selection in this study can be linked not only to the origin of the fresh fish but these species could be more resistant to the high salt content, influenced to the fermentation method condition.

\section{Conclusion}

This study is the first to describe yeasts associated with adjuevan according to salt concentration added for fermentation by employing both traditional methods. Seven species were identified, varied following fermentation method used and salt concentration added with Pichia fermentans and Hanseniaspora osmophila as dominants species. So, the yeast diversity found here is similar to as those identified in adjuevan samples collected with traditional producers. The results also showed that Kluyveromyces marxianus and Torulaspora delbrueckii were more tolerant to salt than the others. This work confirmed that yeasts were involved in adjuevan production co-existing with LAB. These yeasts should be tested for their functionality during the fermentation, and some might be useful as starter culture to produce better quality fermented fish adjuevan.

\section{Compliance with ethical standards}

\section{Acknowledgments}

This study was supported by Nangui Abrogoua University of Abidjan (Côte d'Ivoire) and UMR-Qualisud of CIRADMontpellier (France). Special thanks to technical members of UMR-Qualisud of CIRAD for their assistance in this analysis.

\section{Disclosure of conflict of interest}

The authors declare that there is no conflict of interests regarding the publication of this paper.

\section{References}

[1] Kouakou AC, Florent NK, Adjei DT, Didier M and Djè MK.(2013). Production and marketing of adjuevan, fermented fish from Côte d'Ivoire. Agricultural book, 22, 559-67.

[2] Didier M, Le Nguyen DD and Kouakou AC. (2012). Determination of fish origin by Using 16S rDNA or 26S fingerprinting of microbial communities by PCR-DGGE: An Application on fish from different tropical origins. Aquaculture, 6, 93-108. Edition of Intech, Croatia, 390.

[3] Koffi-Nevry R, Ouina TS, Koussemon M and Brou KD. (2011). Chemical composition and lactic microflora of adjuevan, a traditional Ivorian fermented fish condiment. Pakistan Journal of Nutrition, 10, 332-337.

[4] Kouakou AC, N'Guessan KF, Dadie AT, Dje MK and Didier M. (2012). Application of culture dependent methods and culture-independent methods (DGGE analysis) to study Lactic acid bacteria ecology of Ivorian fermented fish adjuevan. Challenges of Modern Technology, 3, 50-56.

[5] Kouakou AC, N'Guessan KF, Durand N, Dadie AT, Didier M and Djè MK. (2012). Molecular bacterial characterization and free amino acids composition of two Ivorian Traditional Fermented fish. Fisheries Science, 78,1125-1136.

[6] Lopandic K, Zelger S, Banszky LK, Eliskases-Lechner F and Prillinger H. (2006). Identication of yeasts associated with milk products using traditional and molecular techniques. Food Microbiology, 23, 341-350.

[7] Kouakou AC, Cisse M, Kossonou E, Brou kD, Dje KM and Didier M. (2012). Identification of yeasts associated to the fermented fish "adjuevan" of Ivory Coast by using the molecular technique PCR- DGGE. African Journal of Microbiology Research, 6(19), 4138-4145. 
[8] Martin A, Cordoba JJ, Aranda E, Cordoba MG and Asensio MA. (2006). Contribution of a selected fungal population to the volatile compounds on dry-cured ham. International Journal of Food Microbiology, 110, 8-18.

[9] Jacques N and Casaregola S. (2008). Safety assessment of dairy microorganisms: the hemiascomycetous yeasts. International Journal of Food Microbiology, 26, 321-326.

[10] Simoncini N, Rotelli D, Virgili R and Quintavalla S. (2007). Dynamics and characterization of yeasts during ripening of typical Italian dry-cured ham. Food Microbiology, 24, 577-584.

[11] Bohuon P. (1995). Dehydration-impregnation ternary solutions: transportation study of water and gel solutes and products of animal origin. PhD Thesis, University of Montpellier II, Montpellier, France.

[12] El Sheikha AF, Condur A, Isabelle Metayer, Le Nguyen DD, Gerard L and Didier M. (2009). Determination of fruit origin by using 26S rDNA fingerprinting of yeast communities by PCR-DGGE: preliminary application to Physalis fruits from Egypt. InterScience (Wiley), 26, 567-573.

[13] Cocolin L, Manzano M, Cantoni C and Comi G. (2000). Development of a rapid method for the identification of Lactobacillus spp. isolated from naturally fermented Italian sausage using a polymerase chain reactiontemperature gradient gel electrophoresis. Letter Applied Microbiology, 126-129.

[14] Leesing R. (2005). Identification and validation of specific markers for traceability of aquaculture fish for import/export. PhD dissertation, University of Montpellier 2, Montpellier, France.

[15] Barat JM, Gallart-Jornet L, Andres A, Akse L, Carlehog M and Skjerdal OT. (2006). Influence of cod freshness on the salting, drying and desalting stages. Journal Food Engineering, 73, 9-19.

[16] Bellagha S, Sahli A, Farhat A, Kechaou N and Glenza A. (2006). Studies on Salting and Drying of sardine (Sardinella aurita) : experimental kinetics and modeling. Journal of Food Engineering, 1337-1338.

[17] Anihouvi VB, Saalia F, Sakyi-Dawson E, Ayernor GS and Hounhouigan JD. (2011). Response surface methodology for optimizing the fermentation conditions during the processing of cassava fish (Pseudotolithus sp) into Lanhouin. International Journal of Engineering Science and Technology (IJEST), 3, 7085-7095.

[18] Achinewhu SC, Amadi EN, Barimalaa JS and Eke J. (2004). Microbiology of naturally fermented fish (Sardinella sp.). Journal of Aquatic Food Product Technology, 13(1), 47-53.

[19] Anihouvi VB, Sakyi-Dawson E, Ayernor GS and Hounhouigan JD. (2007). Microbiological changes in naturally fermented cassava fish (Pseudotolithus sp.) for lanhouin production. International Journal of Food Microbiology, 116, 287-291.

[20] Sanni A, Asiedu M and Ayernor G. (2002). Microflora and chemical composition of momoni, a Ghanaian fermented fish condiment. Journal of Food Composition and Analysis, 15(5), 577-83.

[21] Paludan-Muller C, Madsen M, Sophanodora P, Gram L and Peter LM. (2002). Fermentation and microflora of plaasom, a Thai fermented fish product prepared with different salt concentrations. International Journal of Food Microbiology, 73, 61-70.

[22] Andrade MJ, Cordoba JJ, Sanchez B, Casado EM and Rodriguez M. (2009). Evaluation and selection of yeasts isolated from dry-cured Iberian ham by their volatile compound production. Food Chemistry, 113, 457-463.

[23] Alvarez-Martin P, Florez AB, Lopez-Diaz TM and Mayo B. (2007). Phenotypic and molecular identification of yeast species associated with Spanish blue-veined Cabrales cheese. International Dairy Journal, 17, 961-967.

[24] Asefa DT, Trond Møretrø, Gjerde RO, Solveig Langsrud, Kure CF, Sidhu MS, Truls Nesbakken and Skaar I. (2009). Yeast diversity and dynamics in the production processes of Norwegian dry-cured meat products. International Journal of Food Microbiology, 133, 135-140.

[25] Cocolin, L, Urso R, Rantsiou K, Cantoni C and Comi G. (2006). Dynamics and characterization of yeasts during natural fermentation of Italian sausages. FEMS Yeast Research, 6, 692-701.

[26] Nielsen DS, Jacobsen T, Jespersen L, Koch AG and Arneborg N. (2008). Occurrence and growth of yeasts in processed meat products: implications for potential spoilage. Meat Science, 80, 919-926.

[27] Sanz A, Martin R, Ma Bele'n M, Pablo EH, Gonza'lez I and García Lacarra T. (2005). Development of a PCR-culture technique for rapid detection of yeast species in vacuum packed ham. Meat Science, 71, 230-237. 